\title{
Universal Design as a Paradigm for Providing Health Interventions for Older Adults 1
}

\section{PETER J. SNYDER}

There's ageism in everything. I don't give a hoot. It isn't what other people think; it's what you think. But it's hard to come to terms with getting older. Cyndi Lauper (1953 - )

American Musician

Universal design is the design of products and environments to be usable by all people, to the greatest extent possible, without the need for adaptation or specialized design. Ronald L. Mace (1942 - 1998)

American Architect, Originator of concept of Universal Design

Universal Design is a broadly applied approach within the industrial design (ID) field that has, as its hallmark characteristic, the goal of inclusivity. This design philosophy allows the ID professional to play a role as an extended member of the caregiving team for older adults by creating products, services and solutions with a design ethic that has direct effects on their health and well-being.

\section{The Origin and Basic Tenets of Universal Design}

In the mid-1980's Ronald L. Mace, an architect, industrial designer, and a polio victim confined to a wheelchair from age nine, coined the term Universal Design. His experience as a person with disabilities, ones that his doctors thought warranted institutionalization, led to his belief that good design should accommodate everyone. As a boy, and as someone who had to be carried up and down the steps, he designed and modified many of the products he needed to navigate the world in the 1950's and 60's. As an adult, his ideas led to fundamental changes of the North Carolina building code, the state in which he lived, and these innovations eventually became
Care Weekly 2021;5:12-16 Published online May 17, 2021, the national model for barrier-free building and the design of built environments (1). Over much of the past half-century, this model has had an extraordinary impact on the field of industrial design, and it has been continually relied on as designers seek to create better products, places, and systems. Designers add to and/or adjust the tenets of Universal Design to reflect current conditions, to more closely understand the underlying needs of their users, and to invent more relevant solutions. The principles of Universal Design are as important today as they were when they were developed in the late 1980s; and they are important to consider when designing for an aging population.

Universal Design is good design. We tailor the basic tenets of universal design to consider their applicability in creating new products or services for older adults, and these decisions are best informed by first understanding the physical, sensory, psychological and cognitive effects of the aging process - in both health and disease. Hence, before we review the biology and psychology of aging, we will first briefly consider the Universal Design model.

\section{The Seven Principles of Universal Design (2)}

\section{Principle One: Equitable Use}

The design of product, places and systems must be useful and appealing to people with diverse abilities.

- Identical use when possible, equivalent use when necessary

- Avoid segregation or stigma

- Equal access to provisions for safety, privacy and security

- Appealing design for all users http://dx.doi.org/10.14283/cw.2021.3

Corresponding to: Peter J. Snyder, Ph.D. Department of Art \& Art History, College of Arts \& Sciences, and Department of Biomedical \& Pharmaceutical Sciences, College of Pharmacy, The University of Rhode Island, Kingston, RI, USA, pjsnyder@uri.edu 


\section{Principle Two: Flexibility}

The design must accommodate a wide range of individual preferences and abilities.

- Provides choices in methods of use.

- Facilitates users' accuracy and precision.

- Adaptation to user constraints and pace.

\section{Principle Three: Simplicity}

The design is easy to understand or intuitive, regardless of past experience, knowledge base, language skills or level of concentration.

- Consistent with users' expectations.

- Eliminate unnecessary complexity.

- Provide effective cues, feedback or prompts.

\section{Principle Four: Perceptibility}

The design communicates necessary information effectively to the user, regardless of ambient conditions or the user's sensory abilities.

- Uses different modes (pictorial, verbal, tactile) for redundant presentation of essential information.

- Highlights essential information.

- Provides compatibility with a variety of techniques or devices used by people with sensory limitations (e.g., hearing aids, walkers, glasses).

- Maximizes «legibility» of essential information.

\section{Principle Five: Tolerance for Error}

The design minimizes the hazards and the adverse consequences of accidental or unintended actions.

- Useful elements are accessible, and hazardous elements are sequestered or eliminated.

- Fail-safe features and warning signals are provided.

- Not dependent on sustained vigilance.

\section{Principle Six: Low Effort}

The design can be used efficiently and comfortably and with minimal strain or fatigue.

- Minimizes forceful or sustained effort.

- Minimizes need for repetitive actions.

- Allows user to maintain a comfortable body position.

\section{Principle Seven: Accessibility}

The design is accessible for an expected range of body sizes, postures, mobility or sensory functions.

- Comfortable reach and clear sight lines.

- Accommodates variations in hand size and grip strength.

http://www.care-weekly.com/ Vol 5, 2021
- Minimize physical barriers for use.

Universal Design is often collectively referred to by other terms, including Accessible Design, Adaptable Design, Usable Design, User-Focused Design and Design for All. Although there are some slight semantic distinctions between the definitions of these terms, they are all very similar. In this book, we often refer to Universal Design as Inclusive Design. This latter term was coined in 2000 , in a government document from the United Kingdom, in which it was defined as referring to "products, services and environments that include the needs of the widest number of consumers». The origin of this maxim stretches back to the European social ideals that emerged in aftermath of World War II, and the notion of inclusive design extends well beyond addressing the needs of persons with disabilities to the delivery of mainstream solutions for all segments of society, including accessible healthcare and housing. Inclusive Design has a set of six principles: inclusivity, responsivity, flexibility, convenience, accommodation and pragmatism.

Towards the end of the 20th century, and after the clumsy period of badly executed universal design attempts in public spaces, the design community began to recognize that - if done properly - the environments and products designed for those differently abled were not only usable by most people, but actually preferred. Housing designs that «fit» people with functional limits began to move from narrow building code compliance that met the specialized needs of a few (e.g., nursing facilities and group homes), to a more inclusive designs for everyone. In their excellent textbook on Universal Design (2001), Preiser and Ostroff (3) state that "Universal Design (UD) is a new-old concept, rooted in the disability movement but applicable to the majority of the world's societies. UD is not a trend, but an enduring design approach that assumes the range of human ability is ordinary, not "special".

As the physical, social, cognitive and other changes with aging are indeed ordinary, and because these changes often require the consideration of supportive design solutions, and because our aging population is such a massive and rapidly growing segment of our society, it is imperative for designers to consider how best to apply the universal design model to meet the needs and desires of our elders. 
The Impact of Universal Design on the Health and Well-Being of Older Adults

Universal design encourages the design of objects, products, services and systems that actively encourage older adults to remain included as vital, necessary and important members of our larger society. By designing in a way that accounts for the physical, sensory, cognitive and psychological course of healthy aging, we minimize the deleterious effects of the many negative aging stereotypes on the health and happiness of our elders.

Simply put, the extent to which we design objects, services or systems that are inclusive for users of all age groups, that do not segregate or stigmatize one subset of the population, that do not blatantly remind the user of physical or cognitive impairments or loss of function, and that are visually and/or physically pleasing to use, the more that designers can do to combat the stigma of aging. And, by intentionally reducing exposure to such stigma, we are providing measurable, direct health benefits. Before we provide a thoughtful example of how this may be done in practice, let's first explore the harmful effects of aging stereotypes on the health and even the lifespans and risk of mortality of our older adult population.

\section{The Effects of Negative Aging Stereotypes on Cognitive Functioning}

Ageism is a term coined by the psychologist Robert Butler, in 1969, to refer to the pervasive sociocultural and institutionalized prejudice against older persons, based on negative stereotypes of aging in our society. These negative stereotypes have been well-described by others (4), and they include such widely held assumptions as (5):

- Alzheimer's disease is to be expected with old age

- Older workers are less productive than younger workers

- Sickness and disability come with old age

- Older people cannot learn

- Old people are sweet and kind and at peace with the world

- Old people are weak and helpless

- Old people have no interest in or capacity for sexual activity.

- Old people are boring and forgetful

- Old people are unproductive

- Old people are grouchy and cantankerous
- Old women are a burden on everyone

- Old people are past being consulted about anything - even their own lives.

- The majority of older people are set in their ways, unable to change

- The majority of older people view themselves as being in poor health

While a number of these stereotypes may seem silly at first glance, they are nonetheless widely held beliefs in our society and, when faced with these beliefs each day (whether through obvious discrimination or in more understated or subtle ways), the effects of these negative stereotypes directly lead to poor health consequences for older adults. As an example, the influence of such negative stereotypes on memory, reasoning and problem solving abilities has been shown to be quite strong, even when the older adult is not consciously thinking of these beliefs.

Many psychological studies conducted over the past few years have shown that when older adults complete memory tests, after first reading a short article suggesting that the elderly have impaired memory functions, they actually perform at least $20 \%$ worse on the memory test than those who did not first read the article. If an older person is presented with the mere proposition that they have impaired memory abilities, this suggestion leads to clear, unmistakable and detrimental effects on their actual cognitive test performance. These studies highlight the powerful effects that exposure to negative stereotypes has on older adults or, frankly, any special group who are subject to such negative biases.

There is, however, a positive lesson in this work. In 2013, Drs. Sarah Barber and Mara Mather, at the University of California - Davis School of Gerontology, showed that this entire effect can be completely reversed if the older adults are "primed" with exposure to a message that suggests that they have something to gain by performing well on the same tests. Specifically, when older adults are provided with information to suggest that good performance on cognitively challenging tasks leads to "brain exercise" that helps to prevent cognitive decline, exposure to that positive message leads to improved cognitive performance. Hence, the valence of the implicit message (a negative stereotype versus a positive message about avoiding loss) that the older individual receives has a direct, large effect on actual cognitive performance (6).

There are other threads of evidence pointing to the fact that the societal messages that we provide http://www.care-weekly.com/ Vol 5, 2021 
to our elders directly affect their health and wellbeing. Consider that, if significant memory loss in old age is an entirely natural and normal byproduct of aging, then we would see essentially the same levels of impairment in older adults across cultures and geographic regions. And yet, this is hardly the case. In a classic study comparing Chinese and American older adults on standard memory tests, the Chinese participants outperformed their American counterparts (7). Although a portion of these group differences might be due, in part, to genetic and biologic differences between persons of Asian vs. Caucasian descent, the researchers concluded that the majority of this difference can be accounted for in the differing cultural views on aging. Whereas the Chinese participants reported more positive views on aging, the American subjects were far more pessimistic and more readily voiced their beliefs that their memory is impaired because they are old. It seems, then, that these negative stereotypes about aging, in American culture, "lead people to believe in the truth of those stereotypes, and this becomes a self-fulfilling prophecy" (8). What makes this even worse is that the effects of chronic exposure to these negative stereotypes can last for decades, and the extent to which people subscribe to them as being "true" in mid-life actually is predictive of (impaired) performance on memory tests several decades later! (9)

\section{The Effects of Ageism on Other aspects of Health}

Human aging is, of course, a normal process of life that, over time, is characterized by physical decline and increasing health issues. However, over the past decade there has been an increasing amount of very credible research to show that how older adults are perceived and, even more importantly, how they perceive themselves can either greatly hasten or slow the pace of their own physical decline (8).

Why does the belief in negative stereotypes about oneself impact physical health, such as the severity of arthritis, or cardiovascular disease, or even the length of one's lifespan? There has been much research over the past decade to suggest that the extent to which older adults believe in the ageist stereotypes listed above may actually impact their own "will to live". That is, the belief in these stereotypes seems to influence one's feeling that they have personal control, or agency, over their own health. And, this leads to a "downward spiral" such that older adults with these beliefs tend not to engage in preventative health behaviors or to actively seek medical attention when necessary (10). Perhaps unsurprisingly, older adults who indicate that they readily accept and believe that these aging stereotypes are the source of their infirmities demonstrate greater impairments in terms of heart disease, hearing loss and arthritis than their "more positive" counterparts. Although with this type of research it is often difficult to tease apart which comes first, the infirmity or the fixed belief system, there is little doubt that one leads to a worsening of the other (probably in both directions). Moreover, recent research has shown that older adults with more positive ideas about their mental and physical health actually live between 2 and 5 years longer than their counterparts who readily believe these negative stereotypes (8).

So, what is at the root of how belief in such negative ageist stereotypes can lead to more rapid physical decline and death? There are at least three possibilities, and they may all be partly to blame. First, to the extent that older adults who subscribe to such beliefs implicitly "give up" their own abilities to exert personal control, they tend not to engage in healthy behaviours that may prevent physical decline (e.g., regular exercise, a healthy diet) and they tend not to actively seek medical care as vociferously. Second, it is possible that the constant belief in such stereotypes, leading to a negative selfperception and a diminished sense of self-worth carries with it increased levels of chronic anxiety and depression; and with this, social withdrawal, diminished pleasure in previously enjoyable activities, and reduced interest in engaging socially with family and peers. All of these boil down to living with increased stress, and such psychological stress leads to hormonal changes in the brain that has direct, deleterious effects on the immune system and on cardiovascular health. In point of fact, even the simple and brief exposure of healthy older adults to aging stereotypes leads to a rapid cardiovascular stress response! (11)

\section{The Role of the Designer in Mitigating the Effects of Ageism to Protect Health}

The practicing industrial designer can choose to function as an extension of the healthcare team by creating products that diffuse the pernicious influence of negative stereotypes about aging. There are many practical ways by 


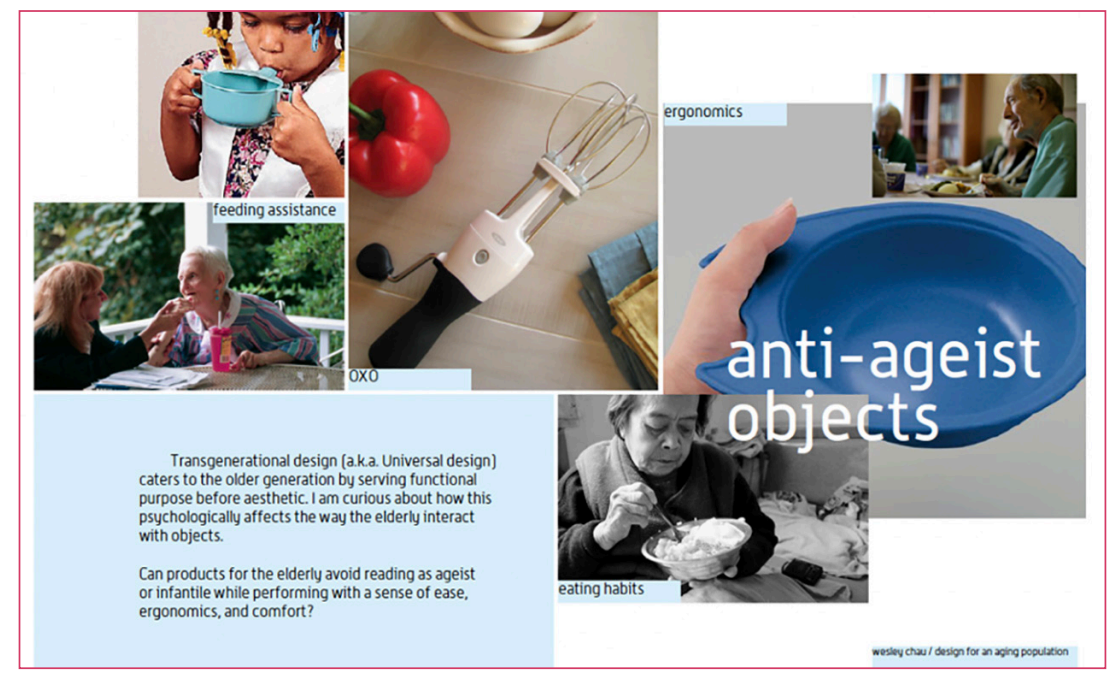

Panel 2-1 in this chapter, but they should go a step further - they should not provide any visual messaging that they were designed for the care of the elderly. No one wants to live in a home that looks like the furniture or implements inside were lifted out of a hospital or nursing facility. If the objects and products around us remind us that we are losing physical capabilities, then we will be more apt to believe this is so, and the downward spiral described above gets worse.

The accompanying article provides a case study to demonstrate just how elegantly such goals can be met in the design of an object as simple as a drinking mug. Although a former student of mine, Brandy Taylor, sought to design her new line of mugs with aging and arthritic hands in mind, she meant them to be broadly appealing across all age ranges. After surveying most of the mugs that are currently marketed for older adults, she felt that she could create a product that was less clinical, medicinal and depersonalizing in its physical appearance, compared to similar products already marketed to the intended user group.

Conflicts of Interest

None

\section{References}

1. Saxon, W. (1998). Ronald Lawrence Mace. The New York Times. http://www.nytimes.com/1998/07/13/us/ronald-1-mace58-designer-of-buildings-accessible-to-all.html Accessed: 03 November, 2016.

2. Duncan, R. (2014). Universal Design. Center for Excellence in Universal Design, National Disability Authority. http:// universaldesign.ie/What-is-Universal-Design/ConferenceProceedings/Universal-Design-for-the-21st-Century-IrishInternational-Perspectives/ Accessed: 03 November, 2016.

3. Preiser, W.F.E., Ostroff, E. (2001). Universal Design Handbook. New York, NY: McGraw Hill Professional Series.

4. Nelson, T.D. (2015). Ageism. In T.D. Nelson (Ed.), Handbook of prejudice, stereotyping, and discrimination. New York, NY: Taylor and Francis.

5. Schmidt, F. (2011). Top 20 stereotypes of older people. The Senior Citizen Times. https://the-senior-citizen-times. com/2011/11/23/top-20-stereotypes-of-older-people/ Accessed: 18 October, 2016.

6. Barber, S.J., Mather, M. (2013). Stereotype threat can both enhance and impair older adults' memory. Psychological Science, 24(12): 2522-2529.

7. Levy, B.R., Langer, E. (1994). Aging free from negative stereotypes: Successful memory in China and among the American deaf. Journal of Personality and Social Psychology, 66: $989-997$.

8. Nelson, T.D. (2016). Promoting Healthy Aging by Confronting Ageism. American Psychologist, 71(4): 276 - 282.

9. Levy, B.R., Zonderman, A.B., Slade, M.D., \& Ferrucci, L. (2012). Memory shaped by age stereotypes over time. The Journals of Gerontology Series B, Psychological Sciences and Social Sciences, 67: $432-436$.

10. Sargent-Cox, K., Anstey, K.J. (2015). The relationship between age-stereotypes and health locus of control across adult age groups. Psychology \& Health, 30: 652 - 670.

11. Allen, J.O. (2016). Ageism as a risk factor for chronic disease. Gerontologist, 56(4): $610-614$. 